\title{
Erratum to: Response trajectories reveal conflict phase in image-word mismatch
}

\author{
Floris T. van Vugt $\cdot$ Patrick Cavanagh
}

Published online: 27 April 2012

(C) Psychonomic Society, Inc. 2012

\section{Erratum to: Atten Percept Psychophys DOI 10.3758/s13414-011-0261-0}

The abstract that appears below was inadvertently left out of the original article.

\begin{abstract}
In the present study, response trajectories were used in a picture-word conflict task to determine the timing of intermediate processing stages that are relatively inaccessible to response time measures. A marker was placed above or below the word ABOVE or BELOW so that its location was congruent or in conflict with the word's meaning. To report either word location (above or below the marker) or word meaning, participants moved a mouse upward toward the appropriate
\end{abstract}

top left or right answer corner on the display screen. Their response trajectories showed a number of distinctive features: First, at about $200 \mathrm{~ms}$ after stimulus onset (the "decision moment"), the trajectory abruptly began to arc toward the appropriate answer corner; second, when the word's meaning and position were in conflict, the trajectory showed an interruption that continued until the conflict was resolved. By varying the SOA of the word and marker onsets, we found that the word meaning and word position became available at approximately $325 \mathrm{~ms}$ and $251 \mathrm{~ms}$, respectively, after their onsets, and that the delay to resolve conflicts was about $138 \mathrm{~ms}$. The timing of these response trajectory events was more stable than any extracted from the final response times, demonstrating the power of response trajectories to reveal processing stages that are only poorly resolved, if at all, by response time measures.

The online version of the original article can be found at http://dx.doi.org/ 10.3758/s13414-011-0261-0.

Electronic supplementary material The online version of this article (doi:10.3758/s13414-012-0300-5) contains supplementary material, which is available to authorized users.

F. T. van Vugt • P. Cavanagh

Laboratoire Psychologie de la Perception, CNRS UMR 8158,

Université Paris Descartes,

Sorbonne Paris Cité Paris, France

F. T. van Vugt $(\bowtie)$

IMMM HMTMH,

Emmichplatz 1,

Hannover, Germany

e-mail: f.t.vanvugt@gmail.com 